\title{
Knowledge management to develop comprehensive networking of university-industry collabora- tion in technology and innovation performance
}

\author{
Emiliana Sri Pudjiartia $^{*}$, Edy Lisdiyono ${ }^{a}$ and Rini Werdiningsih ${ }^{a}$
}

\begin{tabular}{l}
$\frac{{ }^{a} \text { Universitas } 17 \text { Agustus } 1945 \text { Semaran }}{\text { C H R O N I C L E }}$ \\
\hline Article history: \\
Received: July 22, 2021 \\
Received in revised format: Sep- \\
tember 16, 2021 \\
Accepted: December 12, 2021 \\
Available online: December 12, \\
2021 \\
\hline Keywords: \\
Knowledge management \\
University-industry cooperation \\
Regulatory implementation \\
Innovation performance
\end{tabular}

\begin{abstract}
A B S T R A C T
Universities are an integral part of the skills and innovation supply chain for businesses that are multidimensional, sustainable, quality, and enduring in the long term. In pursuing this role, universities are encouraged to establish a university-industry cooperation (UIC) context that supports faculty and students to engage in business activities. Collaboration is very important for universities, because universities are not only research universities, but must reach the level of learning colleges. The results of the research found that implementing UIC regulations affected the performance of university academic innovation, it also found that the knowledge management mechanism was an important factor to improve the performance of university academic innovation, and the implementation of regulations also played a role in developing knowledge management and performance of university academic innovation.
\end{abstract}

\section{Introduction}

Indonesian universities face various major challenges that must be addressed wisely. Economic globalization and the information technology revolution are two major forces that affect the world of higher education. Universities are required to build an innovation system to contribute to the nation's economic development (Etzkowitz, 2003; Sadma, 2021). To respond to this dynamic, Minister of Education, Culture, Research, and Technology, Nadiem-Makarim made a leap so that higher education does not only focus on understanding theory, but is able to produce applicable graduates, namely by launching the Merdeka Learning-Independent Campus (MBKM) program. One of which is learning through university-industry collaboration (UIC), which is regulated in the Minister of Education and Culture Regulation No. 3 of 2020.

The university is an integral part of the supply-chain of skills and innovation for business. However, it is not a linear supplierbuyer transaction, nor is it a single product/service acquisition, but is multidimensional, sustainable, quality and durable in the long term. This attribute can only be created through the UIC (Wilson, 2012). Collaboration is very important for universities, because universities cannot achieve excellence if they are only teaching-oriented, and if they are only research universities without being able to reach the level of learning universities. The task of the university is how to integrate the existence of the university with the industrial world so that graduates are expected to get a place in the formation of employment opportunities, besides that the synergy between universities and industry is expected to reduce the burden on the government in terms of providing employment. In other words, the university's job is to help the government provide employment by cooperating with business and industry. Therefore, the best way to fulfill these requirements is through collaboration, because of the many benefits of UIC, such as reduced costs, multidisciplinary processing, reputation with collaborators, increased expertise and others (Draghici et al., 2015).

* Corresponding author.

E-mail address: emilianapudjiarti.untag.smg@gmail.com (E. S. Pudjiarti)

(C) 2022 by the authors; licensee Growing Science, Canada. doi: $10.5267 /$ j.ijdns.2021.12.008 
Collaboration leads to a series of benefits that have a positive impact on innovation and competitiveness. So that UIC gains wide interest because of the high level of innovation it produces (Guan \& Zhao, 2013; Iqbal et al., 2015). Universities provide an essential infrastructure for scientific research and for creating technological innovations (Etzkowitz, 2003). In addition to the quality of academic research, it also emphasizes the concept of an entrepreneurial university to facilitate the commercialization of technological innovations from universities (Kaloudis et al., 2019). Innovation is a complex process that involves not only innovative companies but also systems of interaction and interdependence between companies and other institutions (Saeidi et al., 2013; Mufti et al., 2019). In this regard, for the development and improvement of innovation system capabilities, collaboration between universities and industry is widely recognized as one of the key factors (Teirlinck \& Spithoven, 2013). Universities as providers of higher education services must have organizational capabilities, including program development and academic resources; academic operational services; research and innovation; social responsibility; strategic cooperation; IPR development and management. All of this is related to knowledge management which is one of the important enablers in achieving university performance.

Conceptually, knowledge management is an organizational activity in managing knowledge as an asset, so efforts are needed to distribute the right knowledge to the right people and in a fast time, so that they interact with each other, share knowledge and apply it in their daily work in order to improve higher education performance. Knowledge management Žemaitis (2014) is planning, collecting and organizing, leading and controlling data and information that has been combined with various forms of thinking and analysis from various competent sources. The main principle of knowledge management is to encourage universities to achieve what they know. Studies Law and Chuah (2004) and Mardani et al. (2018) state that there is a significant and positive impact of the knowledge management process on innovation as well as a significant and positive effect of codification and personalization approaches on innovation. Darroch and McNaughton (2002) stated that knowledge management as a mechanism is able to make the use of resources more efficient so that they are more innovative and perform better.

The problem experienced by most universities in Indonesia is that the results of research conducted by universities are limited to reports only, eventually only piled up on the bookshelf of the library room or in a file folder on the hard drive. The results of research conducted by the academic community of universities should have a downstream process to the industry or society in need, which in the end the research results can have useful value. Through the transfer of technology, universities as one of the community service institutions have values and roles in increasing innovation. Huang and Chen (2017) found that the implementation of UIC regulations has a positive and significant impact on the innovative climate in universities, and the implementation of UIC regulations reflects the implementation of regulations for the management of R\&D and UIC development.

This research was conducted at a private university in Central Java which has had success in collaborating with the industrial world. From the university's point of view, collaboration is done to gain financial benefits and increase industry knowledge, especially about technology development. In this collaboration, the role of the university is very important, especially as a technology creator, provider of human resources, and aligning changes or economic developments with changes that occur in society. From an industry point of view, the decision to collaborate with industry is influenced by the low level of in-house research and development, the shorter product life cycle and changes in industry research priorities. Based on the description of the background above, the problems raised in this research are: How is the implementation of university-industry regulations in an effort to develop management knowledge to support innovation performance in collaboration between universities and industry.

\section{Literature Review}

\subsection{IUC Innovation Performance}

Under the framework of the National Innovation System, innovation means the creation of knowledge or technology (Metcalfe \& Ramlogan, 2005). Innovation is widely recognized as a core renewal process in organizations (Murata et al., 2014). There are many definitions for innovation. Gunday et al. (2011) see that innovation is not just a good thought, but is an intensive work organized so that it becomes an important component of every organizational unit and management system. Sedziuviene and Vveinhardt (2010) stated that the main and fundamental purpose of innovation is to generate new knowledge that can develop and find the best solutions for society. Innovation is a complex phenomenon that involves a series of processes towards a set goal (Guan \& Zhao, 2013).

Previous studies concluded that research findings from higher education in the form of scientific articles (Boldt-Christmas et al., 2006), and patents (Pouris, 2009) are direct indicators of evaluating knowledge accumulation. Scientific articles are very important in the development of industrial technology. Scientific papers are the only medium for reporting scientific achievements. In addition to scientific articles, patents are also a key indicator of research performance, knowledge diffusion, and innovative activities (Pouris, 2009). The benefits of patents are documents containing findings, which are commercially available and provide information about the pace of innovative activities that can be easily accessed, while parents are a means to protect original inventions, and patent data is readily available complete with operational tools in policy making. 


\subsection{Knowledge Management}

Knowledge management is nothing new, having been used for thousands of years, but it wasn't until the 1990s that executives, universities, managers, and even the World Bank started talking about knowledge management. What is new is that knowledge management is becoming a consciously promoted and organized practice, as it has strategic value for organizations to develop innovation and competitive advantage and improve performance (Gunday et al., 2011). Knowledge management is a knowledge-based management concept, which connects individuals to individuals and individuals to information in order to create a competitive advantage, and this is an important prerequisite for the innovation process to be successful, because knowledge is a critical resource and is the basis of a resource-based view (Draghici et al., 2015). The focus on managing knowledge becomes the company's main capability and becomes the most important economic resource that dominates and even becomes the only resource that excels in competition Gunday et al. (2011), even Du Plessis (2007), innovation depends on knowledge. Ivascu et al. (2016) state that the ability to acquire knowledge has a positive effect on innovation. Based on the description above, the first hypothesis proposed is:

\section{H1: Knowledge management has a positive and significant impact on IUC Innovation Performance.}

\subsection{IUC Regulation Implementation}

The implementation of regulations in UIC reflects the implementation of regulations for the management of R\&D and development of UIC. Formal UIC management mechanisms are useful in collaboration between organizations, as stated by Thune \& Gulbrandsen (2011) that institutionalization facilitates increased interaction between universities and industry. A formal UIC management mechanism can be thought of as an arrangement for coordination and control in collaboration. In addition, the formal UIC management mechanism as a control process allows inter-organizational relationships to be reproduced and perpetuated. Several studies have explored the effect of regulatory implementation on university academic innovation performance in the context of UIC. From a behavioral control perspective, organizational agency theory involves monitoring the behavior of members and then establishing productive behavior. Behavioral control is usually associated with rules and regulations designed to ensure that member behavior is in line with the manager's goals. Gross \& Feldman Barrett (2011) argue that innovation requires simultaneous regulation of autonomy and control to promote creativity. Cardinal (2001) conducted an empirical investigation and found that the implementation of regulations can improve the outcomes of radical innovation efforts in the pharmaceutical industry. Based on this description, the proposed hypothesis is:

H2: IUC regulation implementation has a positive and significant effect on knowledge management.

$\mathbf{H}_{3}$ : IUC regulation implementation has a positive and significant effect on IUC Innovation Performance.

\section{Method}

This research is basic research conducted for the development of science. The research population is lecturers at private universities in the Cluster 2 group. The number of samples is determined according to the minimum number of samples according to the Structure Equation Model (SEM). The sampling technique used is random sampling. The data collection period lasts from February to March 2021 online. Questionnaires were distributed to 368 respondents who were randomly selected using a google form sent via Whatsaap. Only 324 respondents filled out the questionnaire, but 293 lecturers filled out the questionnaire completely and tested fit.

The measurement of the concept of knowledge management using indicators adopted from Draghici et al. (2015) is measured by three dimensions, namely: external knowledge acquisition has 3 indicators, internal knowledge acquisition has 3 indicators, and knowledge creation has 6 indicators. The concept of IUC Regulation Implementation was adopted from Huang \& Chen (2017); IUC Innovation Performance was adopted from Mardani et al. (2018) with three dimensions, namely: innovation speed, innovation quality and innovation quantity. A 7-point Likert scale ( $1=$ Strongly Disagree to $7=$ Strongly Agree) was used as the measurement scale in this study.

Structural Equation Model (SEM) is used to test Confirmatory Factor Analysis (CFA), which is to test the indicators of the construct (Jensen \& Urban, 2007). CFA testing requirements with Kaiser-Meyer-Olkin (KMO) and Bartlett's, with test conditions if the correlation between variables is greater than 0.5 and the research significance level is less than or equal to 0.05 , then the data is declared reliable.

The research was conducted through online questionnaires from February to March 2021. Questionnaire items were measured on a Likert scale with 7 degrees of intensity (1=disagreement, $7=$ Agreement). The respondent's identity questionnaire asked for information about lecturer profiles (gender, age, functional position, specialization, education level, years of service as a lecturer, number of works produced (articles, patents). Socio-demographic characteristics of respondents are presented in Table 1. 


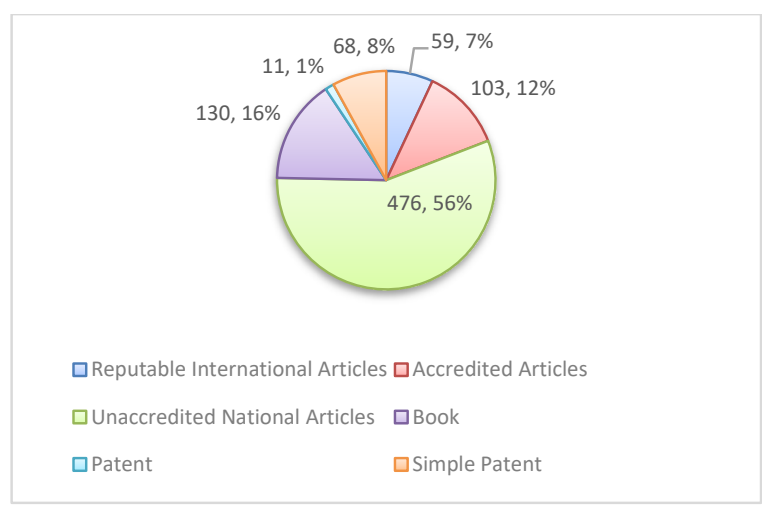

Scientific work

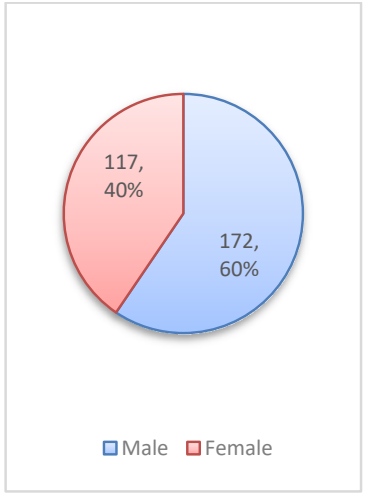

Gender

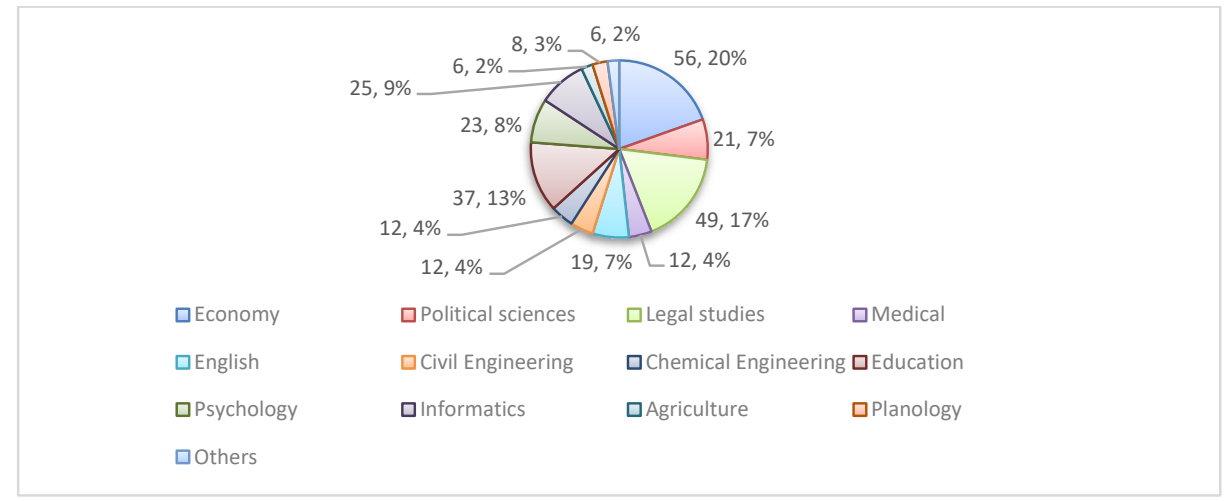

Specialization

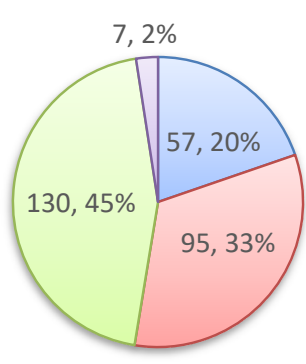

$\square$ Assistant $\square$ Lecturer $\square$ Head Lecturer $\square$ Professor

Academic title

Fig. 1. Respondents' socio-demographic characteristics $(\mathrm{N}=289)$

\section{Result}

\subsection{Exploratory Factor Analysis}

Prior to conducting the Exploratory Factor Analysis (EFA) analysis, we tested Kaiser-Meyer-Olkin (KMO) to measure the adequacy of sampling and Bartlett's Test of Sphericity to investigate the data capability factor. The resulting KMO with a high value of 0.792 is greater than 0.60 and significant, this implies the suitability of the data for EFA and the test statistic is declared significant as indicated by Bartlett's Test of Sphericity $(\mathrm{p}<0.001)$.

Table 1

Kaiser-Meyer-Olkin (KMO) sample adequacy test.

Kaiser-Meyer-Olkin Measure of Sampling Adequacy

.792

\begin{tabular}{lll}
\hline Bartlett's Test of Sphericity & Approx. Chi-Square & 2836.371 \\
& df & 378 \\
Sig & .000 \\
\hline
\end{tabular}

Source: Processed primary data (2021)

\subsection{Dimensional Analysis, Reliability and Validity}

EFA is a method of factor analysis to identify the relationship between manifest variables or indicator variables in constructing constructs. The measure that shows that an indicator is included in a certain indicator in the EFA is the loading factor value. When the factor loading indicator value is greater than one particular factor, the indicator can be grouped into that factor (Table 2). Regarding convergent validity, it was found that all indicators showed significant factor loading $(\mathrm{p}<0.01)$. The reliability of all latent variables is higher than 0.7 , a value considered adequate by (Hair et al., 2014). Similarly, the EVA value is higher than 0.5 . Furthermore, data validity testing is used to determine the extent of the accuracy and accuracy of a measurement instrument in carrying out its measuring function, namely so that the data can be relevant to the purpose of the measurement. Meanwhile, reliability shows how much the degree of the test consistently measures the measured target. The average value describes the response of the respondents to the instrument, showing a positive response because it is above the midpoint value, and the standard deviation above zero explains that the respondents' answers are quite varied. 
Table 2

Measurement Statistics of Construct Scales

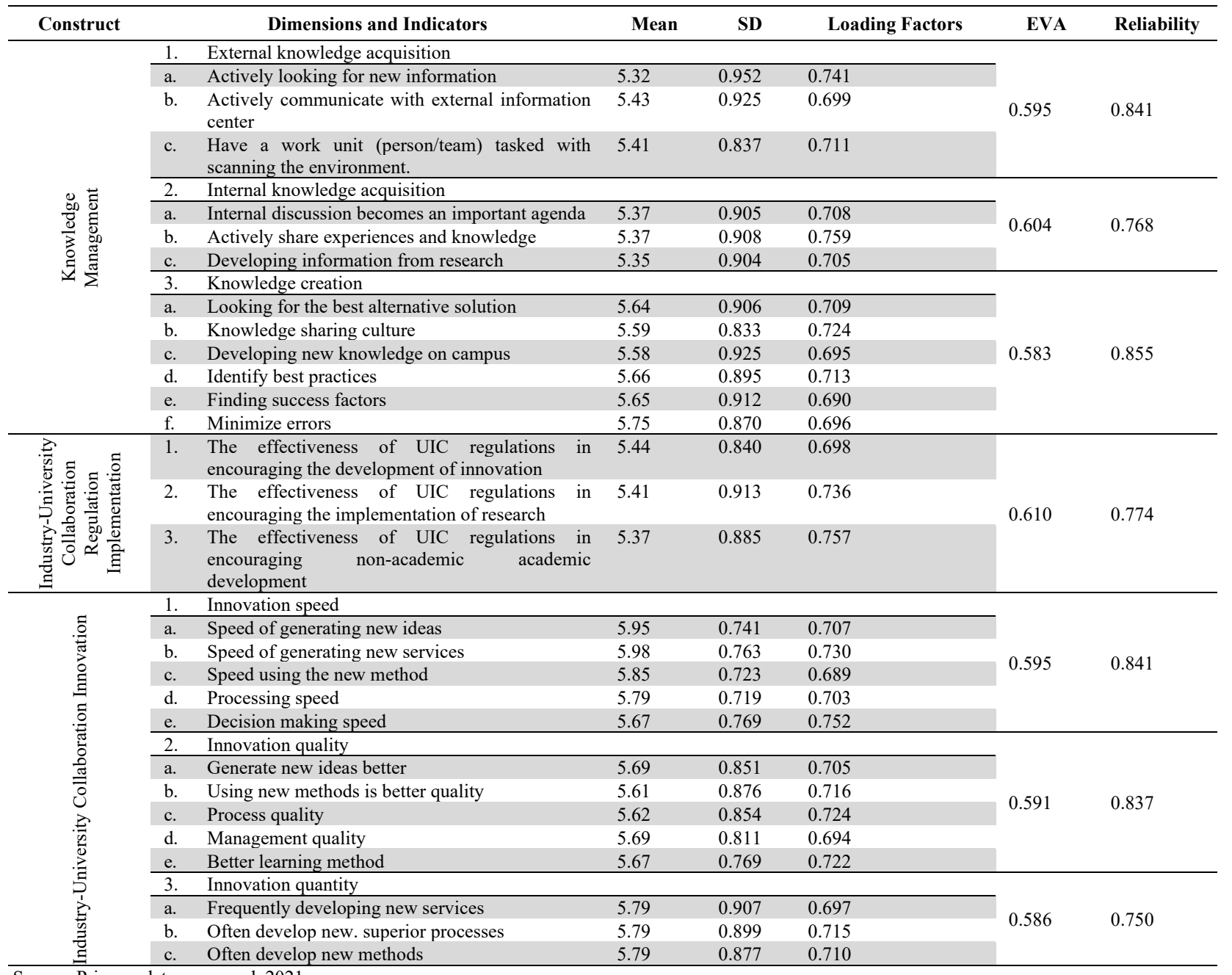

Source: Primary data processed, 2021

\subsection{Second Order of IUC Innovation Performance}

Three IUC-Innovation Performance variables were identified as having an adequate suitability index and were achieved within the recommended threshold (Hair et al., 2014). Evaluation of the model, the estimation criteria used include CFI $=0.987$, TLI $=0.985$, and RMSEA $=0.029$ with the appropriate $95 \%$ confidence intervals. Chi-square statistic, $\chi 2=79.103, \mathrm{df}=64, \mathrm{p}=$ 0.097 , which was statistically significant at 0.05 . The alternative index analysis of the normed chi-square set a threshold of 0.5 with $\chi 2 / \mathrm{df}=1.236$, this coefficient is in accordance with that recommended by Schumacker and Lomax (2004). It was concluded that the overall assessment of the model fit criteria was acceptable for the 13 items of the IUC-Innovation Performance scale using second order CFA analysis in its validation. Fig. 2 below shows the details. The IUC Innovation Performance measurement model which includes unidimensionality, first order, second order has been achieved, so that it can proceed to the next stage.

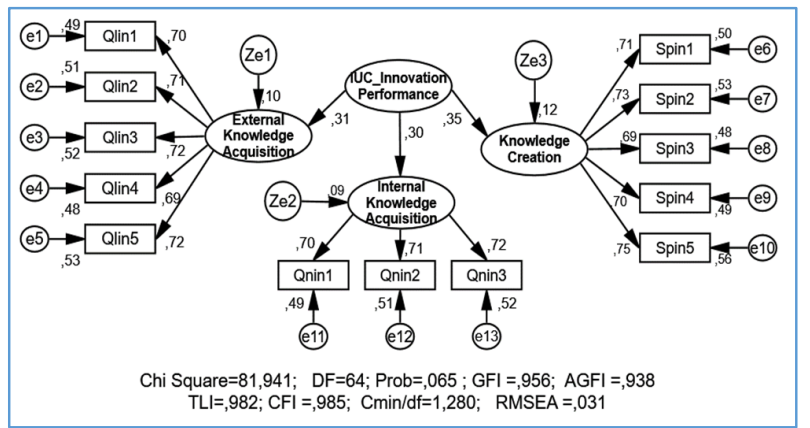

Fig. 2. Second-order CFA IUC-Innovation Performance 


\subsection{Second Order of Knowledge Management}

The three identified knowledge management variables have an adequate conformity index and have been reached within the recommended threshold (Hair et al., 2014). Evaluation of the model, the estimation criteria used include CFI $=0.988$, TLI $=$ 0.985 , and RMSEA $=0.029$ with the appropriate $95 \%$ confidence intervals. Chi-square statistic, $\chi 2=65,788, \mathrm{df}=53, \mathrm{p}=$ 0.112 statistically significant at 0.05 . The alternative index analysis of the normed chi-square set a threshold of $0.5 \mathrm{with} \chi 2 / \mathrm{df}$ $=1.241$, this coefficient is in accordance with that recommended by Schumacker \& Lomax (2004). It was concluded that the overall assessment of the model fit criteria was acceptable for the 15-item knowledge management scale using second order CFA analysis in its validation. Figure 2 below shows the details. The knowledge management measurement model which includes unidimensionality, first order, second order has been achieved, so that it continues to the next stage.

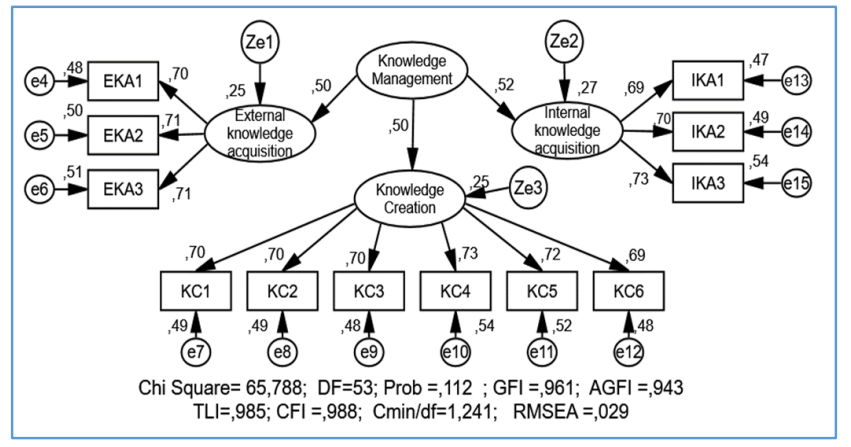

Fig. 3. Second Order of Knowledge Management

\subsection{Structural model assessment}

The model results show that the data fit well. Chi-square significant $\chi 2=379,832$, $\mathrm{df}=344, \mathrm{p}=.089$. CMIN $/ \mathrm{df}$ is 1.104 , well below the maximum limit of $2.0, \mathrm{GFI}=.912$ and $\mathrm{AGFI}=.896, \mathrm{CFI}=.986 ; \mathrm{TLI}=.985 ; \mathrm{CFI}=.986$ is also above .95 , and RMSEA $=.019$ is also suitable because it is below .05. From Fig. 4 it can be concluded that the structural assessment model is declared fit with the data.

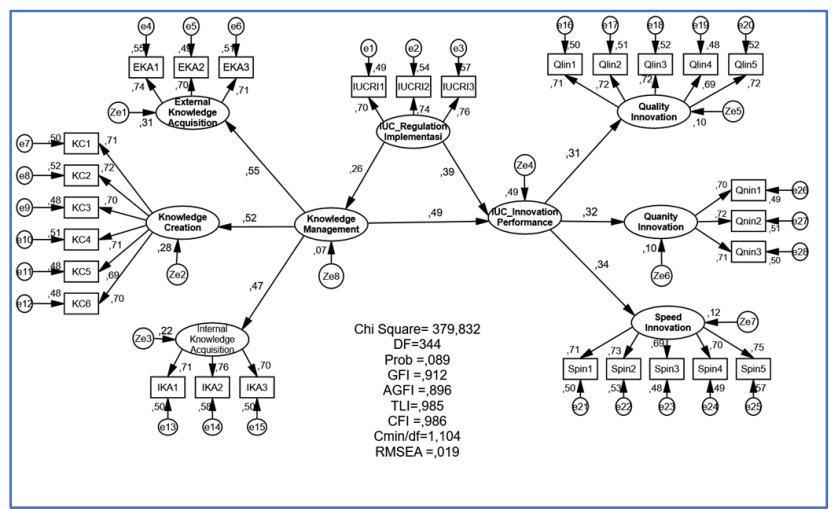

Fig. 4. Results of full structural model

\subsection{Hypothesis test}

Hypothesis testing (Table 3) is based on the value of the critical ratio (CR) and p-value of causality which is built in the framework of thought. If the p-value is less than .05 , then the causality in the research model is concluded to be significant.

Table 3

Standardized Regression Weights

\begin{tabular}{llllll}
\hline Path & & & $\begin{array}{l}\text { Loading } \\
\text { factor }\end{array}$ & $p$ & Result \\
\hline IUC Regulation_Implementation & $\rightarrow$ & Knowledge Management & .257 & .016 & Accepted \\
IUC Regulation_Implementation & $\rightarrow$ & IUC Innovation Performance & .389 & .013 & Accepted \\
Knowledge_Management & $\rightarrow$ & IUC Innovation Performance & .494 & .018 & Accepted \\
\hline
\end{tabular}


This study found that the lecturers had confirmed 6 (six) factors being analyzed. Through SEM analysis concluded that IUC innovation performance as a consequent variable that has been tested significantly from IUC regulation implementation and knowledge management. The analysis also proves that knowledge management is an intervening variable that bridges the antecedent variables to the consequent variables. This study explains that the more effective the IUC Regulation Implementation, the better the development of knowledge management, and the better the development of knowledge management, the higher the IUC innovation performance. This test supports the research of Guerrero et al. (2016), which identifies three types of capital that must be owned in the implementation of UIC, namely human capital, knowledge capital, and entrepreneurial capital, all of which encourage technological growth and contribute to economic value. Because these three capitals have an influence on university performance, namely the results of academic research that can be commercialized in the form of technological innovation. This facilitates opportunities for UIC to encourage the transfer of knowledge from universities to industry (Kaloudis et al., 2019). To facilitate university scientific research and its application to industry, government assistance is needed to provide support in financial policy for research projects to ensure the allocation of the necessary resources. The increasing share of research funding from industry also allows universities to meet financial needs for educational development (Kaymaz \& Eryiğit, 2011). In terms of research, university research can indirectly provide benefits both economically and socially. Economically, of course, the results of research conducted at universities have economic value and can become commodities which can then be utilized by the industry with an agreement mechanism agreed by the parties (e.g. through a license). Socially, of course, the results of this research can be used by the wider community. As a result, universities strengthen their industrial collaboration with outside sponsors and create strategic advantages in the technology diffusion process (Huang \& Chen, 2017). Therefore, university engagement with industry is critical for the development of industrial technology capabilities (Boardman \& Gray, 2010). Several studies have shown that university-industry collaboration (UIC) contributes to a company's technology performance by granting higher quality technology licenses and patents. Kaloudis et al. (2019) and Rybnicek \& Königsgruber (2019) stated that UIC promotes innovative product development and considerable sales growth in the market.

The current study argues that the application of UIC regulations in universities can motivate the development of UIC activities. Two regulations related to UIC development are used to measure the implementation of UIC regulations in universities, namely perceptions of the effectiveness of UIC management regulations in encouraging UIC-related activities and perceptions of the effectiveness of UIC outcome distribution regulations in encouraging lecturers and students to participate in UIC projects. The findings Huang \& Chen (2017) reveal that the development of formal UIC management mechanisms has a strong influence on the performance of academic innovation in subsidized non-UIC universities. This is possible because for universities that are unable to obtain government funding, formal UIC management mechanisms can facilitate more effective use of limited resources. Thus, in order to improve the performance of academic innovation, the formal UIC management mechanism is the most important factor.

\section{Conclusion}

The results of this study explore how three aspects of UIC development at universities (knowledge management; IUC regulation implementation; IU innovation performance) can affect the university's academic innovation performance, as seen from the works of lecturers, the number of papers and patent publications. This study also found that knowledge management mediates the relationship between UIC regulation implementation and academic innovation performance, so that universities are supported in implementing policies to build a culture of knowledge.

Based on these results, several implications can be put forward, namely: The results of the full structural model analysis show that the formal management mechanism of UIC has a significant effect on the performance of university academic innovation. Formal UIC management mechanisms reflect arrangements for control and coordination in collaborative relationships. Universities that hire more industry experts to find potential partners for UIC can facilitate more interaction between universities and industry.

In relation to the implementation of innovation management in higher education, the university leadership can determine the institution/agency/central/work unit at the university level, and explain in detail the institutional aspects and practice guidelines carried out by the innovation management institution. In terms of down streaming research results, of course, the role of innovation management institutions cannot be separated from the role of intellectual property centers, therefore the author tries to make a comparison between the two which can then be weighed and studied in more depth.

The limitation of this research is the research method using cross sectional. Given that the concepts of performance and innovation have a long-term perspective, the conclusions of this study cannot describe reality. Cross-sectional also does not take into account the relationship time-lags between variables. A longitudinal study approach for future research is needed to provide more precise empirical evidence.

\section{Acknowledgment}

The authors are grateful to the Ministry of cultural education, research and technology of the Republic of Indonesia which provides research grants for 2021 and to the students who helped carry out the survey. 


\section{References}

Boardman, C., \& Gray, D. (2010). The new science and engineering management: cooperative research centers as government policies, industry strategies, and organizations. The Journal of Technology Transfer, 35(5), 445-459.

Boldt-Christmas, L., Roos, G., \& Pike, S. (2006, December). Knowledge creation through national innovation systems. In 3rd Asia-Pacific International Conference on Knowledge Management (pp. 11-13).

Cardinal, L. B. (2001). Technological innovation in the pharmaceutical industry: The use of organizational control in managing research and development. Organization science, 12(1), 19-36.

Darroch, J., \& McNaughton, R. (2002). Examining the link between knowledge management practices and types of innovation. Journal of intellectual capital.

Draghici, A., Baban, C. F., Gogan, M. L., \& Ivascu, L. V. (2015). A knowledge management approach for the university-industry collaboration in open innovation. Procedia Economics and Finance, 23, 23-32.

Du Plessis, M. (2007). The role of knowledge management in innovation. Journal of knowledge management.

Etzkowitz, H. (2003). Innovation in innovation: The triple helix of university-industry-government relations. Social science information, 42(3), 293-337.

Gross, J. J., \& Feldman Barrett, L. (2011). Emotion generation and emotion regulation: One or two depends on your point of view. Emotion review, 3(1), 8-16.

Guan, J., \& Zhao, Q. (2013). The impact of university-industry collaboration networks on innovation in nanobiopharmaceuticals. Technological Forecasting and Social Change, 80(7), 1271-1286.

Guerrero, M., Urbano, D., Fayolle, A., Klofsten, M., \& Mian, S. (2016). Entrepreneurial universities: emerging models in the new social and economic landscape. Small Business Economics, 47(3), 551-563.

Gunday, G., Ulusoy, G., Kilic, K., \& Alpkan, L. (2011). Effects of innovation types on firm performance. International Journal of production economics, 133(2), 662-676.

Hair Jr, J. F., Sarstedt, M., Hopkins, L., \& Kuppelwieser, V. G. (2014). Partial least squares structural equation modeling (PLS-SEM): An emerging tool in business research. European business review.

Huang, M. H., \& Chen, D. Z. (2017). How can academic innovation performance in university-industry collaboration be improved?. Technological Forecasting and Social Change, 123, 210-215.

Iqbal, A. M., Khan, A. S., Bashir, F., \& Senin, A. A. (2015). Evaluating national innovation system of Malaysia based on university-industry research collaboration: A system thinking approach. Asian Social Science, 11(13), 45.

Ivascu, L., Cirjaliu, B., \& Draghici, A. (2016). Business model for the university-industry collaboration in open innovation. Procedia Economics and Finance, 39, 674-678.

Jensen, P., \& Urban, Š. (2007). PRAHA2006. Journal of Molecular Spectroscopy, 2(243), 103-104.

Kaloudis, A., Aspelund, A., Koch, PM., Lauvås, Th.A., ...., \& Aadland, T. (2019). How Universities Contribute to Innovation: A Literature Review-based Analysis. Norwegian University of Science and Technology.

Kaymaz, K., \& Eryiğit, K. Y. (2011). Determining factors hindering university-industry collaboration: An analysis from the perspective of academicians in the context of entrepreneurial science paradigm.

Law, K. M., \& Chuah, K. B. (2004). Project-based action learning as learning approach in learning organisation: the theory and framework. Team Performance Management: An International Journal.

Mardani, A., Nikoosokhan, S., Moradi, M., \& Doustar, M. (2018). The relationship between knowledge management and innovation performance. The Journal of High Technology Management Research, 29(1), 12-26.

Metcalfe, J. S., \& Ramlogan, R. (2005). Limits to the economy of knowledge and knowledge of the economy. Futures, 37(7), 655-674.

Mufti, M., Pudjiarti, E., \& Darmanto, S. (2019). Analysis of Second Order Person-Environment Fit on Innovative Work Behavior and Individual Performance. Arthatama, 3(2), 100-113.

Murata, K., Wakabayashi, K., \& Watanabe, A. (2014, January). Study on and instrument to assess knowledge supply chain systems using advanced Kaizen activity in SMEs. In Supply Chain Forum: an International Journal (Vol. 15, No. 2, pp. 20-32). Taylor \& Francis.

Pouris, A. (2009). Quantitative assessment of South Africa's inventive outputs: International patent analysis. South African Journal of Industrial Engineering, 20(1), 13-30.

Rybnicek, R., \& Königsgruber, R. (2019). What makes industry-university collaboration succeed? A systematic review of the literature. Journal of business economics, 89(2), 221-250.

Sadma, O. (2021). The Role of Environmental-Based "Green Startup" in Reducing Waste Problem and its Implication to Environmental Resilience. Research Horizon, 1(3), 106-114.

Saeidi, S. P., Sofian, S., Saeidi, P., Saeidi, S. P., \& Saaeidi, S. A. (2013). Moderating effect of environmental management accounting on innovation and firm performance: review of contemporary literature. J. Basic. Appl. Sci. Res, 3(11), 332-338.

Schumacker, R. E., \& Lomax, R. G. (2004). A beginner's guide to structural equation modeling. psychology press.

Sedziuviene, N., \& Vveinhardt, J. (2010). Competitiveness and innovations: role of knowledge management at a knowledge organization. Engineering economics, 21(5).

Teirlinck, P., \& Spithoven, A. (2013). Research collaboration and R\&D outsourcing: Different R\&D personnel requirements in SMEs. Technovation, 33(4-5), 142-153.

Thune, T., \& Gulbrandsen, M. (2011). Institutionalization of university-industry interaction: an empirical study of the impact of formal structures on collaboration patterns. Science and Public Policy, 38(2), 99-107.

Wilson, T. (2012). A review of business-university collaboration.

Žemaitis, E. (2014). Knowledge management in open innovation paradigm context: high tech sector perspective. Procedia-Social and Behavioral Sciences, 110, 164-173.

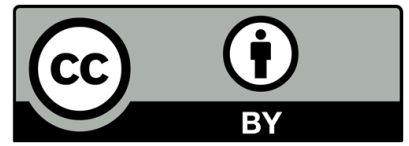

(C) 2022 by the authors; licensee Growing Science, Canada. This is an open access article distributed under the terms and conditions of the Creative Commons Attribution (CC-BY). license (http://creativecommons.org/licenses/by/4.0/). 